\title{
The Conductance Volume Catheter Technique for Measurement of Left Ventricular Volume in Young Piglets
}

\author{
STEVEN C. CASSIDY AND DAVID F. TEITEL \\ Cardiovascular Research Institute, The University of California, San Francisco, California 94143
}

\begin{abstract}
The conductance catheter has been used extensively in the adult for instantaneous and continuous measurement of left ventricular volumes, but has not been validated for use in the small heart. To determine the accuracy of this technique, we simultaneously measured left ventricular volume by the conductance catheter and biplane cineangiography in nine piglets (2-5 wk of age) over a wide range of volumes experimentally altered by volume infusion, hemorrhage, inferior vena caval occlusion, or administration of phenylephrine, isoproterenol, or propranolol. We performed 110 comparisons and determined parallel conductance of contiguous structures $\left(\alpha V_{c}\right)$ for each comparison using the saline technique. End-systole and end-diastole volumes were estimated by angiography using Simpson's rule. Raw and $\alpha \mathbf{V}_{\mathrm{c}}$-corrected conductance volumes were compared to simultaneously obtained angiographic volumes by multiple regression analyses, using dummy variable coding for the effects of the interanimal variability and the phase of the cardiac cycle. Raw conductance volumes correlated highly with the cineangiographic volumes $(r=0.97)$, and the coefficient of angiographic volumes was near identity $(1.11 \pm 0.04)$. The phase of the cardiac cycle did not have a significant effect. However, $\alpha \mathbf{V}_{\mathrm{c}}$-corrected conductance volumes correlated less well $(r=0.85)$, probably related to the fact that estimated $\alpha V_{c}$ was found to vary with ventricular volume. Thus, the conductance catheter affords a very accurate technique for measuring instantaneous changes in ventricular volume in the small heart, although correction to absolute volumes using the saline technique for estimation of $\alpha V_{c}$ may induce some inaccuracy. (Pediatr Res 31: 85-90, 1992)
\end{abstract}

\section{Abbreviations}

$\alpha \mathbf{V}_{c}$, parallel conductance

Evaluation of left ventricular systolic and diastolic performance in the pressure-volume plane has been widely investigated, and a variety of indices have been derived that shed light on the intrinsic function of the myocardium during contraction, relaxation and passive filling (1-6). Such studies often require generation of repeated pressure-volume loops during hemodynamic perturbations such as occlusion of the inferior vena cava. The ideal technique would continuously measure volume, preferably instantaneously generating values, so that the loops could be

Received April 2, 1991; accepted August 20, 1991.

Correspondence and reprint requests: Steven C. Cassidy, M.D., Division of Cardiology, Children's Hospital, 700 Children's Drive, Columbus, OH 43205.

Supported by Grant-in-Aid 88-N137 from the American Heart Association, California Affiliate. S.C.C. was supported by National Institutes of Health NRSA Training Grant HL07544. observed during on-line acquisition of data. The technique should not perturb the hemodynamic state of the subject. It is particularly important in the young subject to have a technique that is not subject to observer measurement biases, such as may occur in echocardiographic studies, because small chamber size magnifies the importance of such errors. The conductance catheter meets these requirements better than any previously used technique and has been used in the adult animal and human (710). However, validation studies of the conductance technique have not been performed in the small heart. To determine its accuracy in small hearts, we compared volumes measured by the conductance catheter to those simultaneously measured by biplane cineangiography in hearts of young piglets under a variety of volume and contractile conditions.

\section{MATERIALS AND METHODS}

Nine piglets between 2 and $5 \mathrm{wk}$ of age $(6.1-8.8 \mathrm{~kg}$ body $\mathrm{wt})$ were studied on a protocol approved by the Committee on Animal Research at the University of California San Francisco. After sedation with ketamine hydrochloride $(8 \mathrm{mg} / \mathrm{kg})$, general anesthesia was induced by $\alpha$-chloralose $(80 \mathrm{mg} / \mathrm{kg}$ ). A tracheostomy was performed, and ventilation with supplemental oxygen was initiated using a Harvard respirator. Access to the central vasculature was established by the percutaneous placement of $6-$ $7 \mathrm{~F}$ Teflon sheaths (Cook, Bloomington, IN) into both right and left femoral veins and femoral arteries. A Teflon sheath was also placed in the left carotid artery by surgical cutdown in some of the piglets.

Catheters were then introduced into the central vasculature via the sheaths. Using fluoroscopic guidance, a $5 \mathrm{~F}$ Berman angiographic catheter (Arrow, Reading, PA) was advanced from the femoral vein into the pulmonary artery. A 5 F Fogarty atrial septostomy catheter (Baxter Health Care Corp., McGaw Park, IL) with a $1.8-\mathrm{mL}$ capacity balloon was placed into the contralateral femoral vein and positioned in the inferior vena cava at the level of the diaphragm. A 4-5 F high-flow pigtail catheter (Cook) was passed in a retrograde fashion from the femoral artery into the left ventricle. A $6 \mathrm{~F}$ pigtail multielectrode conductance catheter (Webster Laboratories, Baldwin Park, CA), which had a total intraelectrode distance $(4 \mathrm{~cm})$ chosen to slightly exceed the left ventricular apex to aortic valve distance (range $3.5-4 \mathrm{~cm}$ ), was advanced into the left ventricle via the femoral artery or carotid artery sheath. The correct positioning of the distal end of the catheter at the cardiac apex and the proximal electrode just above the aortic valve was confirmed during biplane angiocardiography (Fig. 1).

Left ventricular or arterial pressure was monitored continuously through either the pigtail catheter or the side arm of the femoral artery sheath, using a strain gauge transducer (Statham $\mathrm{P} 23 \mathrm{Db}$, Oxnard, CA) attached to a pressure amplifier and a polygraph (Gould Electronics, Cleveland, $\mathrm{OH}$ ). The conductance catheter was connected to a model Sigma-5 signal-conditioner- 


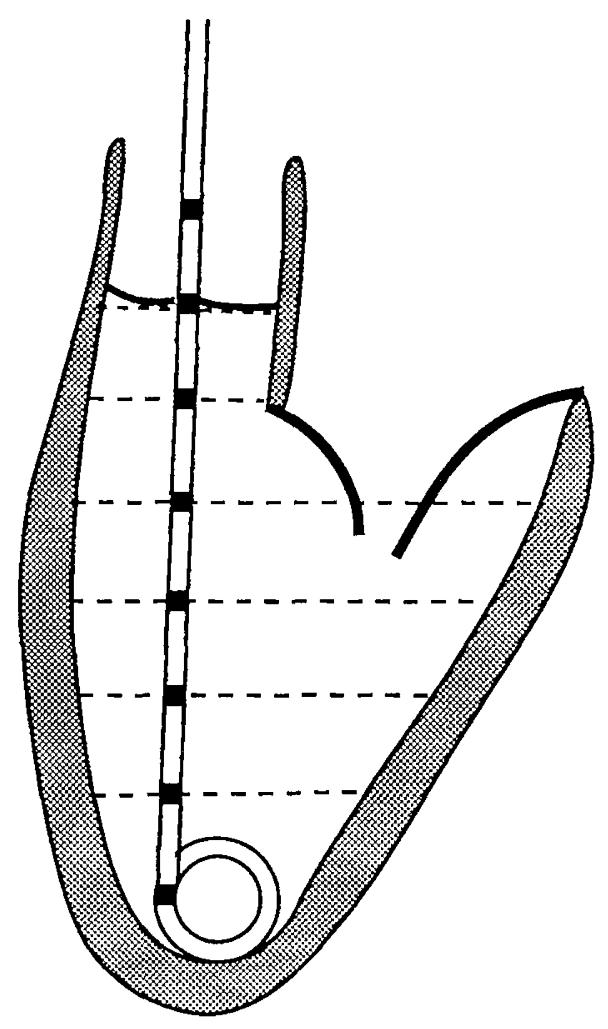

Fig. 1. Diagram of the conductance catheter. A $20-\mathrm{kHz}$ current is applied between the most distal electrode, near the apex of the heart, and the most proximal electrode, above the aortic valve. Conductance of that current is measured between each pair of the other six electrodes.

processor (Leycom, Oestgeest, Netherlands), which supplied a $20-\mathrm{kHz} 0.4-\mathrm{mA}$ root mean squared current, measured the segmental conductances, and calculated the total volume from the segmental conductances. The Sigma- 5 was also used to measure the conductivity of each piglet's blood and of all injectates. Its output was connected to the polygraph amplifiers for monitoring and to an analog-to-digital data card (National Instruments, Austin, TX) inside a Macintosh II microcomputer (Apple Computer, Cupertino, CA). The data were acquired and simultaneously digitized at $200 \mathrm{~Hz}$ and recorded on hard disk for later analysis. The data acquisition and analysis were performed using software developed in our laboratory in the LabVIEW programming environment (National Instruments) on the Macintosh microcomputer.

Between 10 and 17 measurements of ventricular volume were acquired simultaneously by the conductance catheter and cineangiography in each piglet. For each measurement, at least three to seven beats were available from which contrast opacification was sufficient for volume determination by cineangiography. From these beats, maximum diastolic (end-diastolic) and minimum systolic (end-systolic) volumes were measured by the two techniques and mean values were calculated for subsequent data analysis. Data were first acquired under baseline conditions. Subsequently, and in random order, we varied ventricular diastolic and systolic volumes over a wide range by hemorrhage (10 $\mathrm{mL} / \mathrm{kg}$, which was immediately returned at the end of data acquisition), volume infusion (10 mL/ $\mathrm{kg}$ of isoconductive saline), inferior vena caval occlusion, phenylephrine infusion (10$20 \mu \mathrm{g} / \mathrm{kg} / \mathrm{dose}$ ), isoproterenol infusion (0.1-0.2 $\mu \mathrm{g} / \mathrm{kg} / \mathrm{dose}$ ), and propranolol infusion $(1 \mathrm{mg} / \mathrm{kg})$. Heart rate was not controlled, to allow for the greatest changes in volume. We obtained 34 measurements during baseline conditions, eight measurements after volume infusion, four after hemorrhage, 30 during inferior vena caval occlusion, 17 during phenylephrine infusion, 13 during isoproterenol infusion, and four after propranolol infusion. Thus, a total of 110 runs were performed, yielding 220 data sets (110 end-diastolic and 110 end-systolic points) of conductance and angiographic volume estimates. End-diastolic volumes ranged from 4.1 to $29.8 \mathrm{~mL}$, and end-systolic volumes ranged from 1.9 to $20.0 \mathrm{~mL}$, as estimated by angiography.

Conductance measurements. The volume data from the conductance catheter were calibrated using digitized electrical zero and full-scale values. To convert measurements of segmental conductance, $G(\mathrm{i})$, to absolute segmental volumes $V(\mathrm{i})$, the following formula was used:

$$
\mathrm{V}(\mathrm{i})=(1 / \alpha)\left(\mathrm{L}^{2} / \sigma_{\mathrm{b}}\right) \mathrm{G}(\mathrm{i})-\mathrm{V}_{\mathrm{c}}
$$

where $\mathrm{V}(\mathrm{i})$ is the segmental volume, $\alpha$ is a dimensionless slope constant, $\mathrm{L}$ is the interelectrode distance of the catheter, $\sigma_{b}$ is the specific conductivity of blood, and $V_{c}$ is a correction term caused by the parallel conductance of structures surrounding the ventricular cavity (10). The conductivity of the blood was determined frequently throughout the study. $\alpha \mathrm{V}_{\mathrm{c}}$ was determined at the end of each acquisition by the saline method (10) to correct the conductance signal to "absolute" ventricular volume. This was done by transiently changing the conductivity of the blood in the left ventricle and extrapolating to where the blood conductivity was zero. After the radioopaque dye had completely cleared the left ventricle, a small volume $(0.2-0.5 \mathrm{~mL})$ of $3 \%$ $\mathrm{NaCl}$ solution was injected into the pulmonary artery catheter during continuous data acquisition. End-systolic volume was then plotted against end-diastolic volume during the period when the conductivity of the blood was changing, and linear regression was performed. This regression line was then extrapolated to where end-systolic volume equals end-diastolic volume (to where the conductivity of the blood was zero). At this point, $\alpha V_{c}$, all conductance must be through surrounding structures. Conductance volumes throughout the cardiac cycle were determined both without (raw) and with $\left(\alpha \mathrm{V}_{\mathrm{c}}\right.$-corrected) subtraction of $\alpha \mathrm{V}_{\mathrm{c}}$. Enddiastolic and end-systolic volumes for several beats were temporally matched to the angiographic beats during each run.

Cineangeographic measurements. Biplane left ventricular cineangiograms were recorded on videotape in posterior-anterior and lateral projections at a frame rate of $30 / \mathrm{s}$. Before injection, the radioopaque contrast material (Hypaque 76; Sterling-Winthrop, New York, NY) was warmed in a water bath to body temperature, and its conductivity was adjusted to equal that of the blood by dilution with either deionized water (infinitely low

Table 1. Raw conductance volume: results of multiple linear regression analysis*

\begin{tabular}{|c|c|c|c|c|c|c|c|c|c|c|c|}
\hline \multirow[b]{2}{*}{ Variable } & \multirow[b]{2}{*}{$b_{0}$} & \multirow[b]{2}{*}{$\mathrm{V}_{\text {Cine }}$} & \multirow[b]{2}{*}{$\mathrm{C}$} & \multicolumn{8}{|c|}{ Between pigs } \\
\hline & & & & A1 & $\mathrm{A} 2$ & A3 & $\mathrm{A} 4$ & A5 & A6 & A7 & A8 \\
\hline $\mathrm{b}$ & 17.8 & 1.1 & 0.1 & -2.3 & 12.5 & 0.9 & 2.0 & -0.3 & 0.1 & -1.1 & -2.9 \\
\hline SEM & & 0.05 & 0.09 & 0.55 & 0.63 & 0.55 & 0.55 & 0.54 & 0.56 & 0.45 & 0.55 \\
\hline$p$ value & & $<0.001 \dagger$ & $>0.5$ & \multicolumn{8}{|c|}{ Coefficients combined: $<0.001 \uparrow$} \\
\hline
\end{tabular}

* The coefficients $b$ are in $\mathrm{mL}$ except $b_{v \text { cine, }}$ which is in $\mathrm{mL} \cdot \mathrm{mL}^{-1} \cdot \mathrm{b}_{0}$, the intercept (overall mean raw conductance volume). Variables: $\mathrm{V}_{\text {cine }}$ is a continuous variable $(\mathrm{mL})$ representing cineangiographic volume, $\mathrm{C}$ is a dummy variable representing cardiac cycle, and $\mathrm{A} 1$ through $\mathrm{A} 8$ are dummy variables representing the variability among the nine pigs. The regression equation was statistically significant $(p<0.0001)$. The SD of these betweenpig coefficients was $4.87 \mathrm{~mL}$. The $p$ value is that of the corresponding $F$ test for that coefficient or group of coefficients.

$\dagger$ The coefficient or group of coefficients has a significant effect on raw conductance volume. 


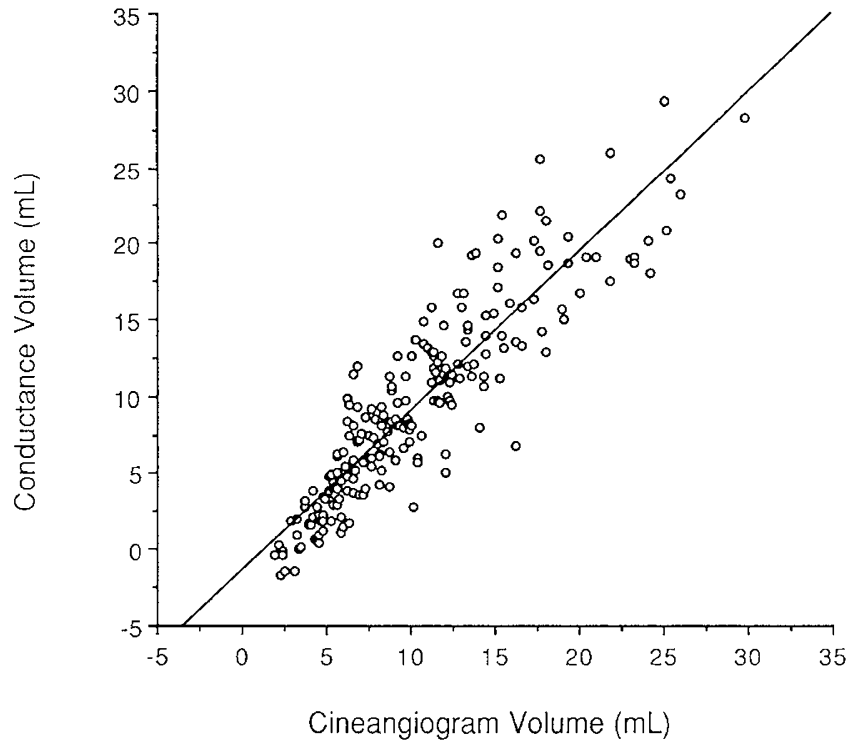

Fig. 2. Scattergram of all of the conductance and cineangiogram data. The conductance volumes have been corrected using the mean $\alpha V_{c}$ for each piglet to remove the different offset volumes between animals. The line shown represents the simple regression between conductance and angiogram volumes. The slope of the line is 1.04 , and $r=0.91$.

conductivity) or saturated sodium chloride solution (very high conductivity). Between 1 and $1.5 \mathrm{~mL} / \mathrm{kg}$ of radioopaque contrast were injected using a pressure injector for each cineangiogram. The volume catheter with known intraelectrode distances was recorded on videotape in a straight cranial-caudal position with the radiographic equipment positioned as it was for the cineangiograms to determine magnification.

Angiographic ventricular volumes were measured from biplane images using Simpson's rule $(11,12)$ on a microcomputer equipped with a video card and software designed for image quantification (Microsonics, Indianapolis, IA). End-diastolic and end-systolic volumes were determined for each beat using frameby-frame comparison of the images. The observer measuring the volumes was blinded to the volume measurements made using the conductance catheter and to the condition under which they were measured. Volumes derived from conductance and angiography were synchronized using the cineangiographic contrast injection (which caused an obvious increase in the volume on the catheter tracing) or by timing of ventricular ectopic beats, which occasionally occurred during contrast injections.

Data analysis. Comparisons between conductance and cineangiographic volumes were made by multiple regression analysis using dummy variables by effects coding (13-15):

$$
\mathrm{V}_{\text {cond }}=\mathrm{b}_{0}+\mathrm{b}_{\mathrm{v}_{\text {cine }}} \mathrm{V}_{\text {cine }}+\mathrm{b}_{\mathrm{c}} \mathrm{C}+\sum_{\mathrm{j}=1}^{8} \mathrm{~b}_{\mathrm{A}_{\mathrm{j}}} \mathrm{A}_{\mathrm{j}}
$$

where the dependent variable $\mathrm{V}_{\text {cond }}$ is the raw or $\alpha \mathrm{V}_{\mathrm{c}}$-corrected conductance volume, the intercept $b_{0}$ is the offset of the conductance volume relative to the cineangiographic volume, $\mathrm{V}_{\text {cine }}$ is the angiographic volume, $C$ is the dummy variable representing the phase in the cardiac cycle (end-systole was assigned a value of 1 , end-diastole, -1 ), and $A_{j}$ represents the dummy variables representing interanimal variability. The coefficients $\left(b_{0}, b_{\text {cine, }}\right.$, etc.) for each variable are the change in $\mathrm{V}_{\text {cond }}$ relative to a change in that variable.

$\alpha V_{c}$ has been found to vary relative to end-systolic and enddiastolic volume in the adult dog (16). To determine whether this relationship existed in the newborn piglet, we performed separate multiple regression analyses of parallel conductance against end-systolic and end-diastolic volume and the set of dummy animal variables, $\mathrm{A}_{\mathrm{j}}$.

\section{RESULTS}

Multiple regression analysis of raw conductance volumes showed a high correlation $(r=0.97)$, an offset volume $b_{0}$ (equivalent to the y-intercept in simple regression) of $17.9 \mathrm{~mL}$, and no significant effect of cardiac cycle (Table 1). The coefficient of the angiographic volume was $1.11 \pm 0.04$, indicating that a change in conductance volume relative to a change in angiographic volume was near identity. This coefficient corresponds to $\alpha$, the slope of the simple linear regression of conductance versus angiographic volume. The strength of the association can be appreciated in Figure 2, which shows a scattergram of all data sets of conductance volume corrected using mean $\alpha \mathrm{V}_{\mathrm{c}}$. This was done to remove the different offset volumes between animals. From simple linear regression analysis of conductance versus cineangiogram volume, the slope of the regression equation was very similar (1.04) to that found by multiple regression analysis. Attempts to fit a polynomial equation to these data did not yield a significantly greater correlation.

When conductance volumes were corrected for individual $\alpha \mathrm{V}_{\mathrm{c}}$ for each run, the correlation of the resultant regression equation was not quite as good $(r=0.85)$, and the coefficient for the angiographic volume was lower (Table 2). Thus, it is likely that the correction of conductance volume using $\alpha \mathrm{V}_{\mathrm{c}}$ introduced some error in the estimation of conductance volume.

When conductance volumes were corrected using the mean of $\alpha V_{c}$ for each piglet rather than the individual $\alpha V_{c}$ for each run, the resultant correlation improved substantially $(r=0.91)$ and the coefficient for the angiographic volume, $V_{\text {cine }}$, increased to 1.1 , similar to the coefficient for the raw conductance volume analysis (Table 3 ). This improvement indicates that there is error in measurement of $\alpha \mathrm{V}_{\mathrm{c}}$ that is partially eliminated by averaging. For actual volume measurements, this small error was not physiologically important. Figure 3 shows data from a representative piglet where the mean $\alpha V_{c}$ for this piglet was subtracted from the raw conductance volume, showing excellent correlation between volumes measured by the two techniques. Again, polynomial regression did not yield a significantly greater correlation.

Regression analyses of $\alpha \mathrm{V}_{\mathrm{c}}$ showed that it varied significantly with both end-systolic and end-diastolic ventricular volumes (Tables 4 and 5). A moderate and similar effect of both volumes on $\alpha \mathrm{V}_{\mathrm{c}}$ was seen, with a predicted change in $\alpha \mathrm{V}_{\mathrm{c}}$ of 0.46 and $0.76 \mathrm{~mL}$ in conjunction with a $1 \mathrm{~mL}$ change in end-systolic volume and end-diastolic volume, respectively.

Table 2. Individual $\alpha V_{c}$ corrected conductance volume: results of multiple linear regression analysis*

\begin{tabular}{|c|c|c|c|c|c|c|c|c|c|c|}
\hline \multirow[b]{2}{*}{ Variable } & \multirow[b]{2}{*}{$\mathrm{b}_{0}$} & \multirow[b]{2}{*}{$\mathrm{V}_{\text {Cine }}$} & \multicolumn{8}{|c|}{ Between pigs } \\
\hline & & & $\mathrm{A} 1$ & $\mathrm{~A} 2$ & A3 & A4 & A5 & A6 & A7 7 & A8 \\
\hline $\mathrm{b}$ & 1.16 & 0.77 & 2.0 & 0.2 & -0.1 & -0.4 & -0.4 & 0.6 & 0.4 & -1.2 \\
\hline SEM & & 0.05 & 0.64 & 0.78 & 0.66 & 0.66 & 0.64 & 0.62 & 0.53 & 0.63 \\
\hline$p$ value & & $<0.001 \dagger$ & \multicolumn{8}{|c|}{ Coefficients combined: $>0.5$} \\
\hline
\end{tabular}

* The SD of the between-pig coefficients was $0.94 \mathrm{~mL}$. See Table 1 for abbreviations and statistical significance. The $p$ value is that of the corresponding $F$ test for that coefficient or group of coefficients.

$\dagger$ The coefficient or group of coefficients has a significant effect on corrected conductance volume. 
Table 3. Mean $\alpha V_{c}$ corrected conductance volume: results of multiple linear regression analysis*

\begin{tabular}{|c|c|c|c|c|c|c|c|c|c|c|}
\hline \multirow[b]{2}{*}{ Variable } & \multirow[b]{2}{*}{$b_{0}$} & \multirow[b]{2}{*}{$\mathrm{V}_{\text {Cine }}$} & \multicolumn{8}{|c|}{ Between pigs } \\
\hline & & & Al & $\mathrm{A} 2$ & A3 & A4 & A5 & A6 & A7 & A8 \\
\hline $\mathrm{b}$ & -2.1 & 1.1 & -0.1 & 2.1 & 0.8 & 0.3 & 0.0 & 1.7 & 0.9 & -0.9 \\
\hline SEM & & 0.04 & 0.53 & 0.59 & 0.54 & 0.55 & 0.54 & 0.55 & 0.45 & 0.55 \\
\hline$p$ value & & $<0.001 \dagger$ & \multicolumn{8}{|c|}{ Coefficients combined: $>0.5$} \\
\hline
\end{tabular}

* The SD of the between-pig coefficients was $1.17 \mathrm{~mL}$. See Table 1 for abbreviations. The $p$ value is that of the corresponding $F$ test for that coefficient or group of coefficients.

$\dagger$ The coefficient or group of coefficients has a significant effect on corrected conductance volume.

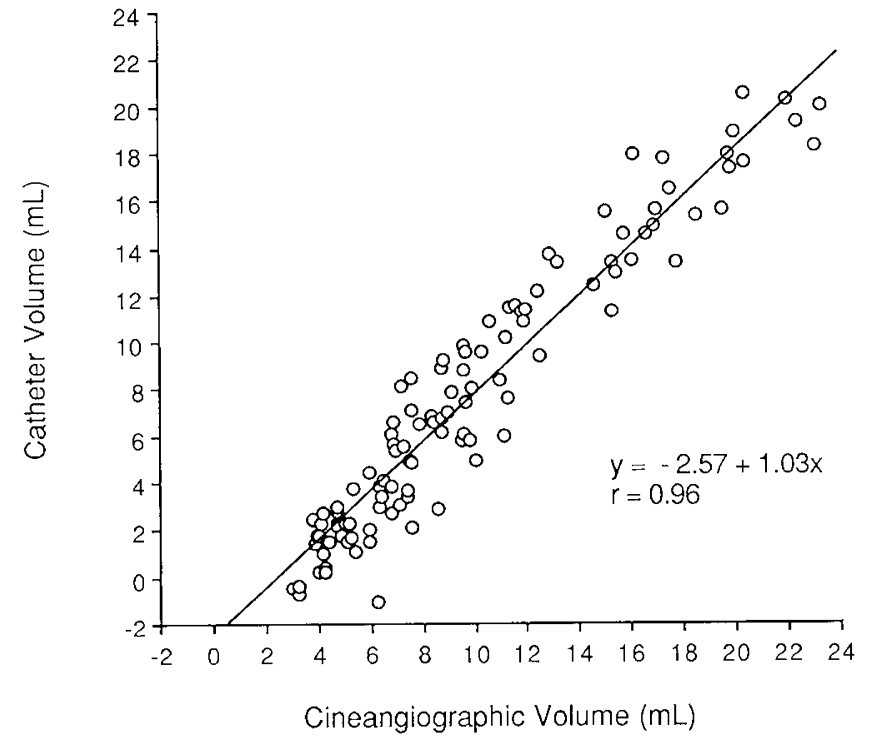

Fig. 3. Scattergram of conductance and cineangiogram data for a representative piglet. The conductance volumes have been corrected using the mean $\alpha \mathrm{V}_{\mathrm{c}}$ for the piglet. The line shown represents the simple regression between conductance and angiogram volumes.

\section{DISCUSSION}

This study demonstrates that the conductance catheter technique is accurate for determining instantaneous ventricular volumes in small hearts. The technique was more accurate when comparing raw rather than $\alpha \mathrm{V}_{\mathrm{c}}$-corrected conductance volumes to cineangiographic volumes. This suggests that correction using the saline method to measure $\alpha V_{c}$ introduced a small error in calculation of absolute volume. We also found that $\alpha \mathrm{V}_{\mathrm{c}}$ varies with ventricular volume, similar to the findings of Boltwood et al. (16) in the adult dog. This is in contrast to the lack of such a relationship in the newborn lamb (17), in which $\alpha \mathrm{V}_{c}$ remained remarkably constant over a very wide range of ventricular volumes.

The conductance catheter has major advantages over other techniques for estimating left ventricular volume. Although left ventricular angiocardiography is an accepted method of measurement of time-varying left ventricular volume, it requires human judgment (18) and is very time-consuming (18-20), even with the use of an image quantification computer. Variability is noted in the studies validating angiocardiography as a technique for volume measurement $(18,21,22)$, and it frequently overestimates true volume $(18,21-24)$. More importantly, angiocardiography alters the loading conditions and contractile function of the ventricle (25). Volumes measured using cross-sectional echocardiography have considerable variability (26-28), often underestimate volume when compared to cineangiography (26, 27 ), and require substantial time for calculation of volume. In addition, echocardiographic definition of the entire endocardial surface is often difficult. Other methods of volume measurement, including computed tomography $(29,30)$, magnetic resonance imaging (31-34), and gated radionuclide imaging (35-39) measure volume from images obtained over many beats. These techniques cannot reflect the beat-to-beat changes in volume required for comparison to simultaneously measured pressures. First-pass radionuclide imaging $(36,40)$ provides images of only one cardiac cycle and similarly cannot reflect beat-to-beat changes in volume. Radionuclide imaging is further limited by its poor resolution and inability to perform multiple studies because of radiation exposure. The technique of volume estimation with similar advantages to the conductance catheter is multidimensional sonomicrometry. However, it can only be performed in animal models and has other disadvantages in the small heart. The placement of six crystals on the heart is technically very difficult, and because of the small size of the heart, may cause significant dysfunction of a relatively large portion of myocardium. The accuracy of the technique has not been established in the small heart. In the adult heart, limited validation studies have shown marked variability in the slope of the relationship between sonomicrometry volumes and "true" volumes (41).

In studies that use estimates of volume based on one or two dimensions of the left ventricle for calculation of indices of cardiac function, assumptions are made regarding both the geometry of the ventricle and uniformity of ventricular motion. These assumptions may not be valid for a great many normal and diseased hearts. Volumes measured using the conductance volume catheter do not strictly require similar geometric assumptions. However, several assumptions of the behavior of the electrical field in the ventricle are required for calculation of volume. These assumptions may not be entirely valid, and work is ongoing to try to better define the electrical field in the ventricle (42).

The determination of $\alpha \mathrm{V}_{\mathrm{c}}$ affects estimation of true volume in two ways: first, $\alpha \mathrm{V}_{\mathrm{c}}$ is dependent on ventricular volume and, second, $\alpha V_{c}$ may vary because of technical problems associated with its estimation. The latter appears more important in this

Table 4. $\alpha V_{c}$ vs end-systolic volume: results of multiple linear regression analysis*

\begin{tabular}{|c|c|c|c|c|c|c|c|c|c|c|}
\hline \multirow[b]{2}{*}{ Variable } & \multirow[b]{2}{*}{$b_{0}$} & \multirow[b]{2}{*}{$V_{\text {Cine }}$} & \multicolumn{8}{|c|}{ Between pigs } \\
\hline & & & $\mathrm{A} 1$ & $\mathrm{~A} 2$ & A3 & A4 & A5 & A6 & A7 & A8 \\
\hline $\mathrm{b}$ & 14.4 & 0.46 & -4.5 & 11.4 & 1.3 & 1.8 & 1.3 & 0 & -1.7 & -2.6 \\
\hline SEM & & 0.08 & 0.99 & 1.2 & 0.95 & 0.98 & 0.86 & 0.84 & 0.79 & 0.84 \\
\hline$p$ value & & $<0.001 \dagger$ & \multicolumn{8}{|c|}{ Coefficients combined: $>0.1$} \\
\hline
\end{tabular}

* The SD of the between-pig coefficients was $4.79 \mathrm{~mL}$. See Table 1 for abbreviations. The $p$ value is that of the corresponding $F$ test for that coefficient or group of coefficients.

$\dagger$ The coefficient or group of coefficients has a significant effect on $a V_{c}$. 
Table 5. $\alpha V_{c}$. vs end-diastolic volume: results of multiple linear regression analysis*

\begin{tabular}{|c|c|c|c|c|c|c|c|c|c|c|}
\hline \multirow[b]{2}{*}{ Variable } & \multirow[b]{2}{*}{$b_{0}$} & \multirow[b]{2}{*}{$\mathrm{V}_{\text {Cine }}$} & \multicolumn{8}{|c|}{ Between pigs } \\
\hline & & & Al & $\mathrm{A} 2$ & $\mathrm{~A} 3$ & A4 & A5 & A6 & A7 & A8 \\
\hline $\mathrm{b}$ & 14.5 & 0.76 & -6.0 & 10.9 & 1.3 & 2.0 & 0.9 & 0.8 & -1.5 & -2.0 \\
\hline SEM & & 0.12 & 1.1 & 1.2 & 0.95 & 0.97 & 0.84 & 0.87 & 0.79 & 0.84 \\
\hline$p$ value & & $<0.001 \dagger$ & \multicolumn{8}{|c|}{ Coefficients combined: $>0.1$} \\
\hline
\end{tabular}

* The SD of the between-pig coefficients was $4.83 \mathrm{~mL}$. See Table 1 for abbreviations. The $p$ value is that of the corresponding $F$ test for that coefficient or group of coefficients.

$\dagger$ The coefficient or group of coefficients has a significant effect on $\alpha \mathrm{V}_{\mathrm{c}}$.

study, because correction for $\alpha \mathrm{V}_{c}$ introduced inaccuracy in the relationship between conductance and angiographic volumes. Several possible reasons for technical problems in determination of $\alpha \mathrm{V}_{\mathrm{c}}$ were present in our study. First, the saline technique assumes that no change in true ventricular volume occurs during injection of hypertonic saline, so that change in apparent volume can be ascribed only to change in conductivity of ventricular blood. To avoid an increase in true left ventricular volume in the small heart, which had absolute end-systolic volumes of 2-4 $\mathrm{mL}$, very small volumes of very hypertonic saline solution are injected. This hypertonic solution itself might change ventricular function as it reaches the coronary circulation and, therefore, will change true ventricular volume. In this study, saline injection probably caused a small but consistent increase in ventricular volume during each estimate of $\alpha \mathrm{V}_{\mathrm{c}}$. This would have a relatively greater impact at the smaller volumes, which might explain the volume dependency of $\alpha \mathrm{V}_{\mathrm{c}}$. Secondly, although every effort was made to insure that the injectate containing radioopaque dye had the same conductivity as the piglet's blood, some error in volume measurement caused by alteration of the blood conductivity was probably introduced by this injection. This may also have contributed to error in measurement of $\alpha \mathrm{V}_{\mathrm{c}}$, which always occurred after angiography. Such an error would only occur in this type of validation study. This would also likely induce volume dependency, because injection of a fixed volume of contrast agent would have different effects in ventricles of different starting volumes. Lastly, we determined $\alpha \mathrm{V}_{\mathrm{c}}$ by performing a linear regression of end-diastolic versus end-systolic volumes for estimates of total volume, rather than determining the individual $\alpha \mathrm{V}_{\mathrm{c}}$ for each catheter segment. Because the best linear fit for each segment (43) appears critical to the accurate determination of $\alpha \mathrm{V}_{\mathrm{c}}$, our technique probably induced some inaccuracy in its determination, although this would not be expected to be volume-dependent. Because averaging of many $\alpha \mathrm{V}_{\mathrm{c}}$ measurements for each piglet improved the correlation of corrected conductance volume and cineangiographic volume, it is apparent that there is more inaccuracy to $\alpha V_{c}$ measurement than systematic variation of $\alpha \mathrm{V}_{\mathrm{c}}$ with volume.

Although averaging the $\alpha V_{c}$ for each animal eliminated some of its variability, this is not a true solution to the problem of error in estimation of $\alpha \mathrm{V}_{\mathrm{c}}$ because variation of $\alpha \mathrm{V}_{\mathrm{c}}$ with volume still exists. A better solution must be found that makes determination of $\alpha \mathrm{V}_{c}$ more reliable in the piglet heart. This perhaps includes use of even smaller volumes of saline injected very slowly, which would not alter true left ventricular volume. If $\alpha \mathrm{V}_{\mathrm{c}}$ appears to be inaccurate or at least volume-dependent in a particular study situation, a decision must be made on how to deal with this problem. One possibility would be to ignore $\alpha V_{c}$ entirely and allow the differences in $\alpha \mathrm{V}_{\mathrm{c}}$ to be represented within interanimal variability in a multiple regression analysis or analysis of variance. Thus, changes in volume rather than absolute volumes would be used in the generation of pressure-volume loops or other techniques for analysis of systolic and diastolic ventricular performance. This is reasonable because many indices of ventricular function do not require knowledge of absolute values of volume but depend upon changes in volume. This is true of many current techniques for estimating ventricular contractility, including the end-systolic pressure-volume relation- ship, the preload recruitable stroke-work index, and the maximum change in pressure per unit time-end-diastolic volume relationships, where the slope of the relationships is most important and curvilinearity beyond the range of measurement makes extrapolation to "unstressed" volume unreliable. Estimates of diastolic performance are primarily directed to isovolumic relaxation, in which rate of pressure fall alone is analyzed, or to passive filling, in which some estimates of compliance are made. Because compliance is determined by a change in pressure relative to a change in volume, true knowledge of absolute volumes is unnecessary. Alternatively, if an estimate of absolute volume is desired for calculation of absolute stress, for example, it may be possible to define the relationship of an accurate estimate of $\alpha \mathrm{V}_{\mathrm{c}}$ versus absolute volume and to correct for this during the estimate of that absolute volume. Other techniques for improving the estimation of $\alpha \mathrm{V}_{\mathrm{c}}$ that may not show the same volume dependency are being developed $(42,44)$. Further studies must be performed before they are accepted for general use.

In summary, estimation of ventricular volume using the conductance catheter is accurate in the young piglet. The conductance catheter method does not disturb loading conditions or contractility and is therefore suitable for repeated studies of left ventricular function. Accuracy decreases when correction to absolute volume is attempted by the use of the saline technique for calculation of $\alpha \mathrm{V}_{\mathrm{c}}$. Despite this problem, the conductance catheter will be a very useful tool in conjunction with accurate measurement of instantaneous ventricular pressure for evaluation of ventricular systolic and diastolic performance in the pressure-volume plane in small hearts.

Acknowledgment. The authors thank James Stoughton for his excellent technical assistance in the catheterizations and the acquisition of the data for this study and Dr. Hugh D. Allen for his review of the manuscript.

\section{REFERENCES}

1. Glantz SA, Parmley WW 1978 Factors which affect the diastolic pressurevolume curve. Circ Res 42:171-180

2. Glower DD, Spratt JA, Snow ND, Kabas JS, Davis JW, Olsen CO, Tyson GS, Sabiston Jr DC, Rankin JS 1985 Linearity of the Frank-Starling relationship in the intact heart: the concept of preload recruitable stroke work. Circulation 71:994-1009

3. Little WC 1985 The left ventricular $\mathrm{dP} / \mathrm{dtmax}$-end-diastolic volume relation in closed-chest dogs. Circ Res 56:808-815

4. Pasipoularides A, Mirsky I, Hess OM, Grimm J, Krayenbuhl HP 1986 Myocardial relaxation and passive diastolic properties in man. Circulation 74:991-1001

5. Suga H, Sagawa K 1974 Instantaneous pressure-volume relationships and their ratio in the cxcised, supported canine left ventricle. Circ Res 35:117-126

6. Van der Linden LP, van der Velde WT, Bruschke AVG, Baan J 1990 Comparison between force-velocity and end-systolic pressure-volume characterization of intrinsic left ventricular function. Am J Physiol 259:H 1419-H1426

7. Cabrera FE, Spinelli JC, Willshaw P, Crottogini AJ, De FE, Clavin O, Valentinuzzi ME, Pichel RH 1988 Detection of left ventricular regional myocardial ischacmia in dogs by intraventricular conductance catheter. Cardiovasc Res 22:185-192

8. Baan J, van der Velde ET, van Dijk AD, Glantz SA, Diethelm L, Lipton MJ 1987 Dynamic volume of the left ventricle at 5 levels by conductance catheter and cine CT scanner. Circulation 76(suppl II):IV-6(abstr)

9. Kass DA, Yamazaki T, Burkhoff D, Maughan WL, Sagawa K 1986 Determination of left ventricular end-systolic pressure-volume relationships by the conductance (volume) catheter technique. Circulation 73(suppl II):586-595 
10. Baan J, van der Velde ET, De Bruin HG, Smeenk GJ, Koops J, Van Dijk AD, Temmerman D, Senden J, Buis B 1984 Continuous measurement of left ventricular volume in animals and humans by conductance catheter. Circulation 70:812-823

11. Goerke RJ, Carlsson E 1967 Calculation of right and left cardiac ventricular volumes. Method using standard computer equipment and biplane angiocardiograms. Invest Radiol 2:360-367

12. Carlsson E, Keene RJ, Lee P, Goerke RJ 1971 Angiocardiographic stroke volume correlation of the two cardiac ventricles in man. Invest Radiol 6:4451

13. Slinker BK, Glantz SA 1985 Multiple linear regression is a useful alternative to traditional analyses of variance. Am J Physiol 255:R I-R 12

14. Glantz SA, Slinker BK 1990 Primer of Applied Regression and Analysis of Variance. McGraw-Hill, New York, pp 50-109

15. Slinker BK, Glantz SA 1990 Missing data in two-way analysis of variance. Am J Physiol 258:R291-R297

16. Boltwood Jr CM, Appleyard RF, Glantz SA 1989 Left ventricular volume measurement by conductance catheter in intact dogs: parallel conductance volume depends on left ventricular size. Circulation 80:1360-1377

17. Teitel DF, Klautz R, Steendijk P, van der Velde ET, van Bel F, Baan J 1991 The end-systolic pressure-volume relationship in the newborn lamb: effects of loading and inotropic interventions. Pediatr Res 29:473-482

18. Chapman CB, Baker O, Mitchell JH, Collier RG 1966 Experiences with a cinefluorographic method for measuring ventricular volume. Am J Cardiol $18: 25-30$

19. Chapman CB, Baker O, Reynolds J, Bonte FJ 1958 Use of biplane cinefluorography for measurement of ventricular volume. Circulation 18:1105-1117

20. Dodge HT, Sandler H, Baxley WA, Hawley RR 1966 Usefulness and limitations of radiographic methods for determining left ventricular volume. Am J Cardiol 18:10-24

21. Kennedy JW, Baxley WA, Figley MM, Dodge HT, Blackmon JR 1966 Quantitative angiocardiography. The normal left ventricle in man. Circulation $34: 272-278$

22. Formanek A, Schey HM, Ekstrand KE, Velasquez G, D'Souza VJ, Glass TA 1984 Single versus biplane right and left ventricular volumetry. A cast and clinical study. Cathet Cardiovasc Diagn 10:137-156

23. Wynne J, Green LH, Mann T, Levin D, Grossman W 1978 Estimation of left ventricular volumes in man from biplane cineangiograms filmed in oblique projections. Am J Cardiol 41:726-732

24. Starling MR, Walsh RA 1985 Accuracy of biplane axial oblique and oblique cineangiographic left ventricular cast volume determinations using a modification of Simpson's rule algorithm. Am Heart J 1 10:1219-1225

25. Chagas ACP, Glantz SA 1988 Angiographic validation of Eigenvolume to measure left ventricular size. Circ Res 62:1237-1246

26. Schiller NB, Acquatella H, Ports TA, Drew D, Goerke J, Ringertz H, Silverman NH, Brundage B, Botvinick EH, Boswell R, Carlsson E, Parmley WW 1979 Left ventricular volume from paired biplane two-dimensional echocardiography. Circulation 60:547-555

27. Mercier JC, DiSessa TG, Jarmakani JM, Nakanishi T, Hiraishi S, Isabel-Jones J, Friedman WF 1982 Two-dimensional echocardiographic assessment of left ventricular volumes and ejection fraction in children. Circulation 65:962-969
28. Gordon EP, Schnittger I, Fitzgerald PJ, Williams P, Popp RL 1983 Reproducibility of left ventricular volumes by two-dimensional echocardiography. $J$ Am Coll Cardiol 2:506-513

29. Reiter SJ, Rumberger JA, Feiring AJ, Stanford W, Marcus ML 1986 Precision of measurements of right and left ventricular volume by cine computed tomography. Circulation 74:890-900

30. Foster CJ, Brownlee WC, Griffin JF, Yates J, Love HG, Isherwood I 1987 A comparison of angiographic and electrocardiographically gated computed tomographic measurements of left-ventricular function. Br J Radiol 60:969974

31. Rehr RB, Malloy CR, Filipchuk NG, Peshock RM 1985 Ventricular volumes measured by MR imaging. Radiology 156:717-719

32. Sechtem U, Pflugfelder PW, Gould RG, Cassidy MM, Higgins CB 1987 Measurement of right and left ventricular volumes in healthy individuals with cine MR imaging. Radiology 163:697-702

33. Markiewicz W, Sechtem U, Kirby R, Derugin N, Caputo GC, Higgins CB 1987 Measurement of ventricular volumes in the dog by nuclear magnetic resonance imaging. J Am Coll Cardiol 10:170-177

34. Underwood SR, Gill CR, Firmin DN, Klipstein RH, Mohiaddin RH, Rees RS, Longmore DB 1988 Left ventricular volume measured rapidly by oblique magnetic resonance imaging. Br Heart J 60:188-195

35. Swain JL, Morris KG, Bruno FP, Cobb FR 1980 Comparison of multigated radionuclide angiography with ultrasonic sonomicrometry over a wide range of ventricular function in the conscious dog. Am J Cardiol 46:976-982

36. Massie BM, Kramer BL, Gertz EW, Henderson SG 1982 Radionuclide measurement of left ventricular volume. Comparison of geometric and countsbased methods. Circulation 65:725-730

37. Parrish MD, Graham Jr TP, Born ML, Jones JP, Boucek Jr RJ, Partain CL 1982 Radionuclide ventriculography for assessment of absolute right and left ventricular volumes in children. Circulation 66:811-819

38. Burns RJ, Nitkin RS, Weisel RD, Houle S, Prieur TG, McLaughlin PR, Druck MN 1985 Optimized count-based scintigraphic left ventricular volume measurement. Can J Cardiol 1:42-46

39. Dell'Italia LJ, Starling MR, Walsh RA, Badke FR, Lasher JC, Blumhardt R 1985 Validation of attenuation-corrected equilibrium radionuclide angiographic determinations of right ventricular volume. Comparison with castvalidated biplane cineventriculography. Circulation 72:317-326

40. Anderson PA, Rerych SK, Moore TE, Jones RH 1981 Accuracy of left ventricular end-diastolic dimension determinations obtained by radionuclide angiocardiography. J Nucl Med 22:500-505

41. Sodums MT, Badke FR, Starling MR, Little WC, O'Rourke RA 1984 Evaluation of left ventricular contractile performance utilizing end-systolic pressure-volume relationships in conscious dogs. Circ Res 54:731-739

42. Steendijk $P$, Jager $H N$, van der Velde ET, Baan J 1988 Left ventricular volume and shape by dual excitation of the conductance catheter. Circulation 78 (suppl II):II-225(abstr)

43. Baan J, van der Velde ET, Steendijk P, Koops J 1989 Calibration and application of the conductance catheter for ventricular volume measurement. Automedica 11:357-365

44. Gawne TJ, Gray KS, Goldstein RE 1987 Estimating left ventricular offset volume using dual-frequency conductance catheters. J Appl Physiol 63:872876 